\title{
Correspondence
}

Editor: Ian Pullen

Contents: Flashbacks following MDMA/Psychiatry and religion/Adult sequelae of child sexual abuse/Prognosis of depression in the elderly/Decontextualisation and mythology/Immigrants from the Indian sub-continent/Case report criticism/Is Dhat culture-bound?/Stability of negative symptoms of schizophrenia/Problem drinking in women/Cyproterone acetate therapy and aggression/Post-stroke rapid cycling bipolar affective disorder/Fluvoxamine withdrawal syndrome.

\section{Flashbacks following MDMA}

SIR: We were interested to read the report by Creighton et al (Journal, November 1991, 159, 713-715), describing 'flashbacks' and paranoid psychosis following methylenedioxymetamphetamine (MDMA) ('Ecstasy') use. We have previously reported paranoid psychosis following MDMA use (McGuire \& Fahy, 1991), and have since identified several other cases with paranoid psychoses (McGuire \& Fahy, in preparation). Both our original cases also described 'flashbacks' of their psychotic experiences, featuring visual images of a wife's imagined infidelity, and of distorted faces, respectively.

In one case of paranoid psychosis described by Creighton et al, initial urinary screening was negative for MDMA (the subject reported recent cessation of MDMA use), but was positive for cannabis. In our experience, concurrent use of other substances, particularly cannabis, is relatively common among MDMA users, tending to confound associations between their symptoms and MDMA use. While urinary screening provides a means of objectively assessing which drugs have been used recently, we have found that screens are often not performed when the subjects present, or are performed without a request for an MDMA assay, as its availability is not always well publicised. More frequent urinary screening should help clarify the relationship between MDMA use and psychiatric phenomena, and seems particularly indicated in view of the current widespread use of the drug.
MCGUIRE, P. \& FAHY, T. (1991) Chronic paranoid psychosis following use of MDMA ('Ecstasy'). British Medical Journal. $302,697$.

Philip McGuire

Institute of Psychiatry

TOM FAHY

De Crespigny Park

London SES 8AF

\section{Psychiatry and religion}

SIR: It was both fascinating and unsettling to see a group of Anglican Ordinands being compared to clinically deluded subjects in a study on the possible benefit of delusions (Roberts, Journal, November 1991, 159 (suppl. 14), 19-28). Psychiatry and religion have often regarded one another with mutual suspicion. Jung's descriptions of parallels between myths and psychosis, like Laing's view of schizophrenia as a potentially constructive inner journey, romanticised madness with dubious mystical overtones. In this study, in which the deluded and the faithful gain equivalent satisfactions from their beliefs, the opposite occurs. Religion is implied to be a belief system designed to reduce anxiety in the same way that a 'psychotic insight' relieves the frightening delusional mood. The suggested existence of successfully deluded individuals, able to incorporate their psychotic experiences into 'normal' life, leads to speculation about the psychopathology of sainthood. Would mystics score highly on the Eysenck Personality Inventory's psychoticism dimension? How far are we from a psychophysiological explanation of religious experience?

There are dangers in attempting to explain all the phenomena of human existence in terms of 'biologism' (Pam, 1990). We must be cautious of developing our biological pseudoreligion in directions which devalue human experience.

PAM, A. (1990) A critique of the scientific status of biological psychiatry. Acta Psychiatrica Scandinavica, 82 (suppl. 362), 1-33.

All Saints Hospital

GaRY Hosty

Lodge Road

Birmingham B18 5SD 